\title{
ANÁLISE DA VARIABILIDADE DA PRECIPITAÇÃO PLUVIOMÉTRICA NA MICRORREGIÃO DE UMBUZEIRO, PARAÍBA
}

\author{
NASCIMENTO, Maxsuel Bezerra do - maxsuel10gba@hotmail.com \\ Universidade Estadual da Paraíba / UEPB \\ ALMEIDA, Nadjacleia Vilar - nadjageo@gmail.com \\ Universidade Federal da Paraíba / UFPB \\ ARAUJO, Lincoln Eloi de- lincolneloi@yahoo.com.br \\ Universidade Federal da Paraíba / UFPB
}

\begin{abstract}
RESUMO: O Nordeste brasileiro apresenta grande variabilidade de precipitação, motivo pelo qual se faz necessário o monitoramento de períodos úmidos e secos, tendo em vista garantir o melhor gerenciamento desse recurso para as propriedades locais. O objetivo principal deste trabalho é verificar e avaliar a variabilidade climática da precipitação pluviométrica na Microrregião de Umbuzeiro, no Estado da Paraíba através da climatologia espaço-temporal da precipitação. Nesse sentido foi utilizado o Índice de Anomalia de Chuva (IAC), para monitorar os períodos secos, chuvosos e suas intensidades. Foram utilizados dados de 7 pontos distribuídos ao longo da microrregião de Umbuzeiro com uma série histórica de 24 anos (de 1994 a 2017). Nesses anos, foram observados dois períodos distintos, um período chuvoso, que vai de março a julho tendo junho como o mês mais significativo, e um período seco, que vai de agosto a fevereiro, sendo outubro o mês mais seco diante esses fatos esse trabalho traz resultados de relevância para área da ecologia, que por meio desses contribuem para que gestores municipais, pequenos proprietários e agricultores tenham informação das épocas chuvosas, mais propícias às atividades agrícolas e entendimento também dos períodos de escassez
\end{abstract}

PALAVRAS-ChaVe: Índice de Anomalia de Chuva, Períodos secos e Períodos chuvosos.

\section{ANALYSIS OF THE VARIABILITY OF PLUVIOMETRIC PRECIPITATION IN THE MICRORREGIÃO DE UMBUZEIRO, PARAÍBA}

ABSTRACT: The Brazilian Northeast presents great variability of precipitation, which is why it is necessary to monitor wet and dry periods, in order to ensure the best management of this resource for local properties. The main objective of this work is to verify and evaluate the climatic variability of rainfall in the Microregion of Umbuzeiro, Paraíba through the space-time precipitation climatology. In this sense, the Rainfall Anomaly Index (IAC) was used to monitor dry and rainy periods and their intensities. Data from 7 points distributed throughout the Umbuzeiro microregion were used with a historical series of 24 years (from 1994 to 2017). In those years, two distinct periods were observed, a rainy period, which runs from March to July, having June as the most significant month, and a dry period, which runs from August to February, October being the driest month in the face of these events. brings results of relevance to the area of ecology, which by means of these of this contribute to that municipal managers, small proprietors and farmers have information of the rainy seasons, more propitious the agricultural activities and understanding also of the periods of scarcity

KEYWORDS: Rainfall Anomaly Index, Dry Periods and Rainy Periods.

\section{ANÁLISIS DE LA VARIABILIDAD DE LA PRECIPITACIÓN PLUVIOMÉTRICA EN LA MICRORREGIÓN DE UNBUZEIRO, PARAÍBA}

RESUMEN: El Nordeste brasileño presenta gran variabilidad de precipitación, motivo por el cual se hace necesario el monitoreo de períodos húmedos y secos, con el fin de 
garantizar la mejor gestión de ese recurso para las propiedades locales. El objetivo principal de este trabajo es verificar y evaluar la variabilidad climática de la precipitación pluviométrica en la Microrregión de Umbuzeiro, Paraíba a través de la climatología espacio-temporal de la precipitación. En ese sentido se utilizó el Índice de Anomalía de Lluvia (IAC), para monitorear los períodos secos y lluviosos y sus intensidades. Se utilizaron datos de 7 puntos distribuidos a lo largo de la microrregión de Umbuzeiro con una serie histórica de 24 años (de 1994 a 2017). En estos años, se observaron dos períodos distintos, un período lluvioso, que va de marzo a julio teniendo junio como el mes más significativo, y un período seco, que va de agosto a febrero, siendo octubre el mes más seco ante estos hechos ese trabajo que a través de estos de éstos contribuyen para que gestores municipales, pequeños propietarios y agricultores tengan información de las épocas lluviosas, más propicias a las actividades agrícolas y entendimiento también de los períodos de escasez.

PALABRAS CLAVE: Precipitación, Índice de Anomalía de Lluvia, Períodos secos y Períodos lluviosos.

\section{INTRODUÇÃO}

O Nordeste brasileiro (NEB) possui uma grande diversidade no seu clima, e que afirmam que a precipitação pluviométrica no NEB é resultado do acoplamento de vários sistemas atmosféricos como, por exemplo, a Zona de Convergência Intertropical (Uvo, 1989), os vórtices ciclônicos de ar superior (Kousky\&Gan, 1981), os Sistemas Frontais (Kousky, 1979) e os Distúrbios de Leste (Espinoza, 1996); todos esses sistemas podem ser modificados através de alguma anomalia atmosférica.

Vale ressaltar que o Estado da Paraíba é o Estado do Nordeste que apresenta uma das maiores variabilidades espaço-temporal das chuvas. A climatologia do Estado pode ser analisada de forma singular, pois as regiões do Agreste/Litoral do Estado apresentam valores anuais acima de 1083,4 mm, em média, seguido da região do Sertão, com valores iguais a $821,9 \mathrm{~mm}$ e pôr fim a região do Cariri/Curimataú, com valores médios em torno de 516,1 mm (ARAÚJO, 2003).

Com base nessa precipitação irregular, faz-se necessário o monitoramento por meio do emprego de índices climáticos. Com base neles, pode-se desenvolver um sistema de acompanhamento das características dos períodos secos e chuvosos, com informações anuais, sazonais ou mensais, com as quais se pode conhecer profundamente a climatologia de uma região, e verificar os impactos que o clima global causa sobre a distribuição pluviométrica local, ou seja, a regionalização da precipitação para determinado local (Da Silva,2009).

Localizada no Agreste paraibano a microrregião de Umbuzeiro predominam pequenas e médias propriedades nas quais se produzem vários produtos que dependem do regime de chuvas da região, que por sinal são irregulares embora a sua precipitação seja maior que o Sertão. A compreensão do regime pluviométrico constitui uma importante abordagem no manejo de recursos hídricos, visto que busca reduzir os conflitos oriundos da escassez e como auxílio no desenvolvimento de políticas e programas que visem a captação e o acondicionamento de água das chuvas (Silva Filho et al., 2015.)

O objetivo principal deste trabalho é verificar e avaliar a variabilidade climática da precipitação pluviométrica na Microrregião de Umbuzeiro, Paraíba 
através da climatologia espaço-temporal da precipitação. Especificamente investigar, através da utilização do Índice de Anomalia de Chuva (IAC) desenvolvido por Rooy (1965), adaptado por Freitas (2005) e readaptado por Araújo et al. (2009).

\section{MATERIAL E MÉTODOS}

O presente trabalho tem como área de estudo a microrregião de Umbuzeiro (Figura 1) que pertence a mesorregião do Agreste Paraibano, localizado no Estado da Paraíba (Figura 2). Com população estimada em 2017 pelo IBGE em 54.519 habitantes, possui uma área total de $1.293,9 \mathrm{~km}^{2}$ e é constituída por 5 municípios, sendo eles: Aroeiras, Gado Bravo, Natuba, Santa Cecília e Umbuzeiro.

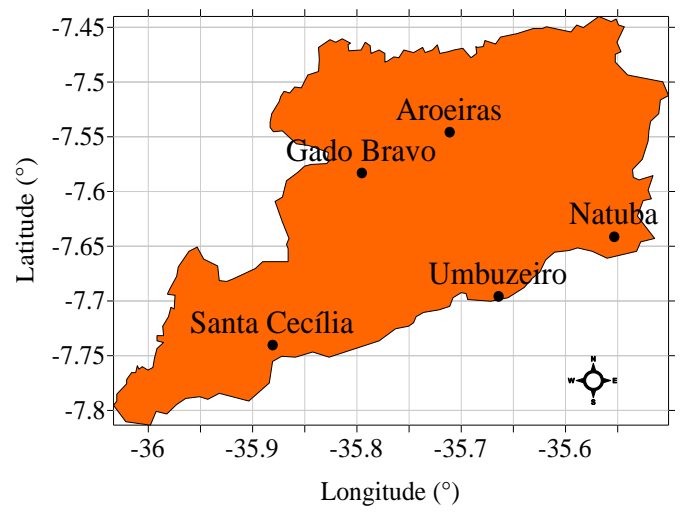

Figura 1 - Localização dos municípios da Microrregião de Umbuzeiro

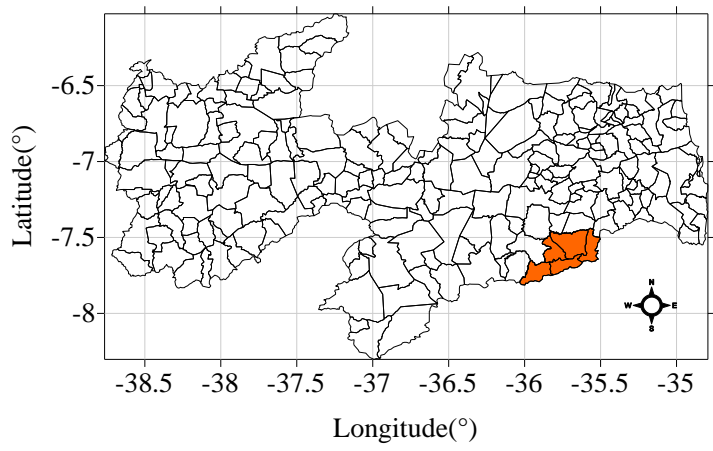

Figura 2 - Localização da Microrregião de Umbuzeiro, em relação ao estado da Paraíba.

Os dados pluviométricos utilizados na pesquisa correspondem as séries mensais de precipitação no período de 1994 a 2017 fornecidos pela AESA (Agência Executiva de Gestões das Águas do Estado da Paraíba), para calcular o Indice de Anomalia de Chuva (IAC), para se verificar a climatologia da microrregião de Umbuzeiro caracterizando os períodos secos e úmidos.

Para a análise temporal foi utilizados 7 pontos meteorológicos que foram localizados dentro dos 5 municípios da microrregião estudada. Portanto, foi utilizada a planilha de dados disponibilizada pela AESA, onde foi calculada a média mensal de precipitação dos municípios de Aroeiras (P1), Gado Bravo (P2), 
Gado Bravo/Fz. Lagoa dos Marcos (P3), Natuba (P4), Santa Cecília (P5), Umbuzeiro (P6) e Umbuzeiro/Mata Virgem (P7) postos pluviométricos, como mostra a figura 3, que também servira de base para o IAC.

Através desses valores foi possível calcular a média mensal, pelo meio da soma da média obtida de todos os meses e dividida pelo total de meses do ano. Em seguida, criou-se uma planilha com a média acumulada e mensal de cada município da sua média histórica de 24 anos para poder fazer a interpolação dos dados, onde foram plotados no software Surfer 8.0 para gerar a figura de espacialização da microrregião de Umbuzeiro.

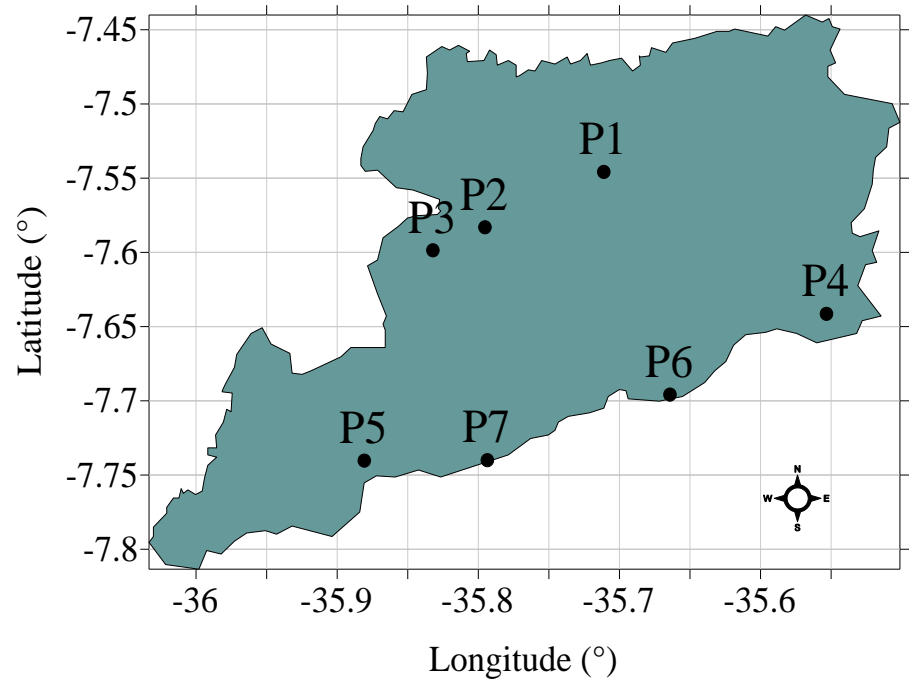

Figura 3 - Localização dos postos pluviométricos da microrregião de Umbuzeiro utilizado na pesquisa.

Vale ressaltar que ao longo da série histórica de dados foram encontradas algumas lacunas; porém as mesmas não representaram alterações significativas nos resultados. Haja vista que de acordo com Nikolova (2007) não deve ser preenchido, pois a reposição de valores em falta na série histórica de precipitação traz mais subjetividade à investigação.

Será usado o IAC anual desenvolvido e utilizado por Rooy (1965) e adaptado por Freitas (2005):

$I A C=3\left[\frac{(N-N)}{(\dot{M}-N)}\right] \quad$ Para anomalias positivas.

$I A C=-3\left[\frac{(N-N)}{(\dot{X}-N)}\right] \quad$ Para anomalias negativas.

Sendo:

$\mathrm{N}=$ precipitação mensal atual $(\mathrm{mm})$

$\hat{N}=$ precipitação média mensal da série histórica $(\mathrm{mm})$;

$\dot{M}=$ média das dez maiores precipitações mensal da série histórica (mm);

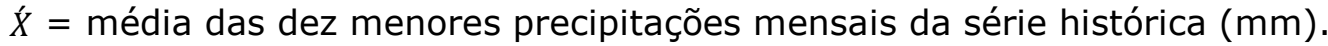


Foram obtidos dados de 7 pontos dentro da microrregião de Umbuzeiro, no qual foi disponibilizado uma série histórica de 24 anos. Sob o ponto de vista climatológico estas séries são consideradas bastante curtas, mas permitem formular hipóteses sobre tendências de aumento ou redução das chuvas em condições atmosféricas extremas conforme Santos et al. (2011).

Segundo os autores e recomendado uma série histórica de 30 anos de dados para se aplicar o IAC, caso a série tenha menos do que 30 anos se recomenda uma adaptação através da qual a quantidade de "medias" utilizadas para se calcular o IAC seja modificada proporcionalmente a quantidade de dados disponíveis; portanto se deve calcular uma série de dados de 24 anos, obtendo as "medias" das 8 maiores e as 8 menores precipitações totais do período analisado. Depois de efetivado o cálculo do IAC, os valores gerados serão classificados de acordo com sua intensidade (Tabela 1).

Tabela 1 - Classes de intensidades do índice de anomalia de chuva (IAC) da Microrregião de Itaporanga.

\begin{tabular}{ccc}
\hline & FAIXA DO IAC & CLASSES DE INTENSIDADE \\
\hline Índice & De 4 acima & Extremamente úmido \\
De anomalia & $2 \mathrm{a} 4$ & Muito úmido \\
De chuva & $0 \mathrm{a} 2$ & Úmido \\
(IAC) & $0 \mathrm{a}-2$ & Seco \\
& $-2 \mathrm{a}-4$ & Muito seco \\
& De -4 abaixo & Extremamente seco \\
\hline
\end{tabular}

Fonte: Araújo et al. (2009)

Os resultados foram analisados e classificados de acordo com a metodologia adaptada por Freitas (2005) e readaptada por Araújo et al. (2009) utilizando uma nova classificação de anos secos e úmidos.

Para entender melhor a diferença entre o período seco e chuvoso na microrregião de Umbuzeiro, foram analisados anos específicos da série histórica e selecionado 2 anos secos e 2 anos úmidos. A escolha desses anos se deve ao fato de que foram anos extremos (extremamente secos e úmidos) com relação aos demais anos da série histórica.

Para análise da hipsometria (relevo) e da declividade foram utilizadas imagens SRTM (Shuttle Radar Topography Mission) com resolução espacial de $30 \times 30 \mathrm{~m}$, disponibilizadas gratuitamente no site da Earth Explore (https://earthexplorer.usgs.gov) administrado pelo Serviço Geológico dos Estados Unidos (U.S.G.S. - United States of Geological Survey). Os referidos mapas foram elaborados utilizando o Sistema de Informação Geográfica ArcGis for Desktop Advanced Educational Academic Departmental Medium Term License - versão 10.6.1. Foi utilizada a ferramenta Spatial Analyst tools.

Portanto, o mapa hipsométrico foi confeccionado com base no MDT e dividido em 12 classes altimétricas, segundo o método de "quebras naturais" (natural breaks) onde a distribuição do conjunto de classes maximiza a diferença entre as classes e identifica pontos de quebra que melhor agrupem valores similares. Deste modo o mapa de declividade foi elaborado com os valores percentuais a partir da imagem SRTM. Foram estabelecidas 6 classes de declividade descriminadas na Tabela 2 (EMBRAPA, 1979; 2004). 
Tabela 2 - Classes de declividade em valores percentuais. Fonte: EMBRAPA

\begin{tabular}{cc}
\hline $\begin{array}{c}\text { Declividade } \\
(\boldsymbol{\%})\end{array}$ & Classes \\
\hline $0-3$ & Plano \\
$3-8$ & Suave ondulado \\
$8-20$ & Ondulado \\
$20-45$ & Fortemente ondulado \\
$45-75$ & Montanhoso \\
\hline
\end{tabular}

\section{RESULTADOS E DISCUSSÃO}

A hipsometria (Figura 4) e a declividade (Figura 5) da Microrregião de Umbuzeiro demostram um relevo dissecado que condiciona um escoamento superficial intenso. A Figura 4 demonstra que a área possui altitudes que vão de 90 a $740 \mathrm{~m}$ com rupturas bruscas no relevo em alguns trechos. As áreas com menor altitude estão próximas aos cursos dos rios, aumentando em direção as suas extremidades.

A declividade caracteriza-se, predominantemente como ondulada a fortemente ondulada, ocorrendo as maiores declividades próximas às vertentes dos rios e riachos que cortam a microrregião e as áreas planas e suave onduladas correspondem aos divisores de água (Figura 5).

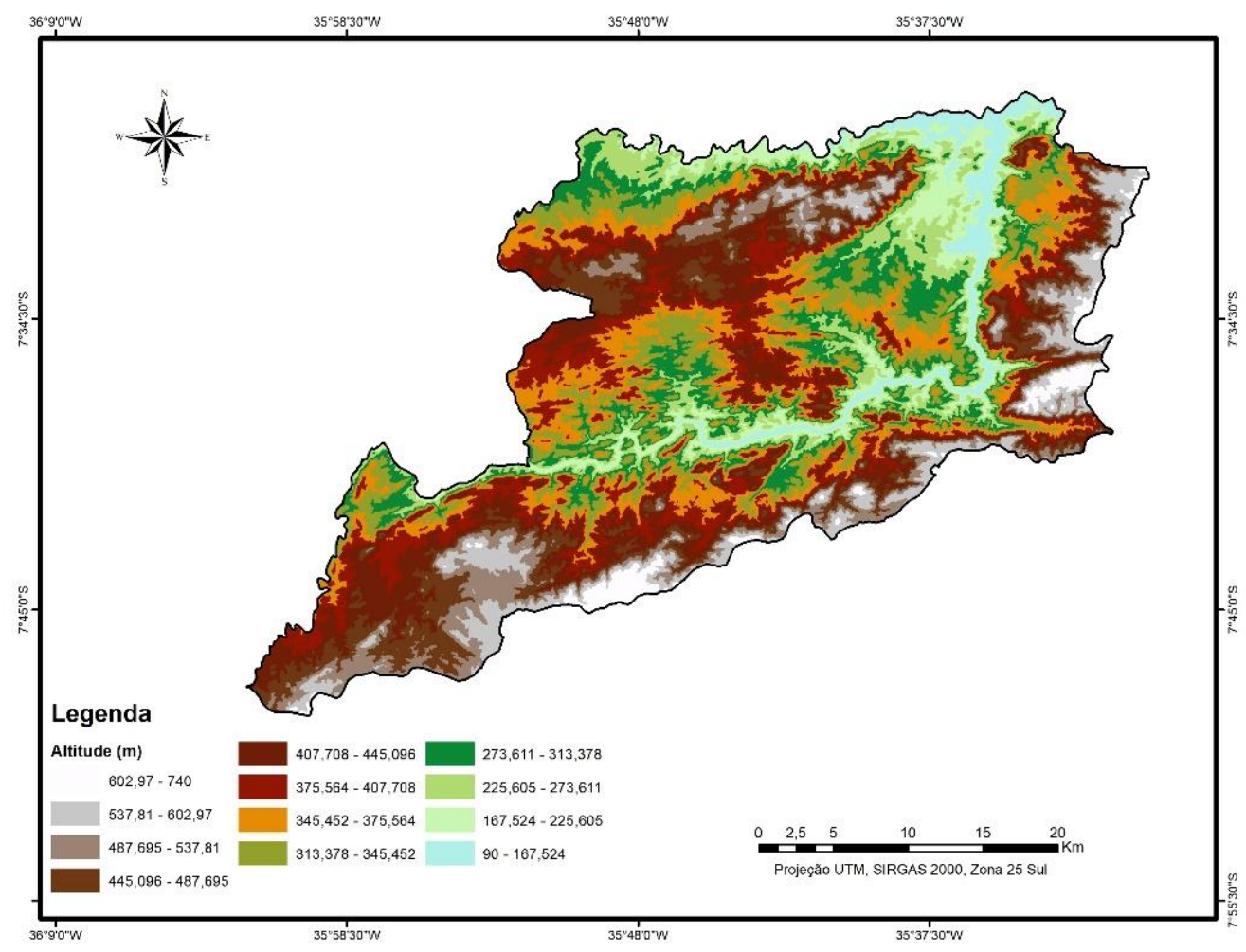

Figura 4 - Hipsometria da microrregião de Umbuzeiro, Paraíba-PB, Brasil 


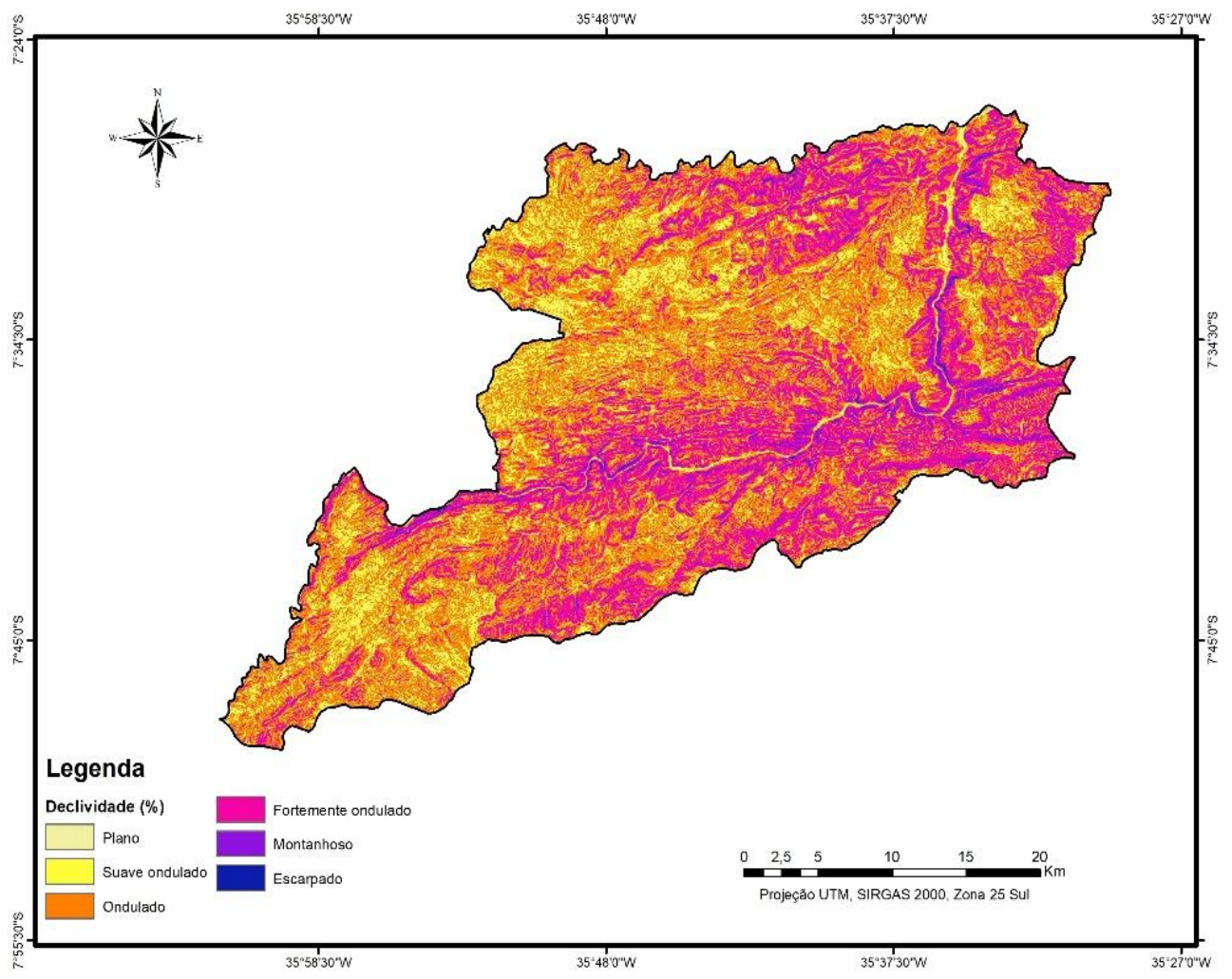

Figura 5 - Declividade da microrregião de Umbuzeiro, Paraíba-PB, Brasil

A microrregião de Umbuzeiro apresenta dois períodos distintos, um período de cinco meses chuvoso e outro com sete meses secos. O período chuvoso ocorre entre os meses de março a julho sendo o mês de junho o mais representativo, no qual atinge precipitação média de $119,9 \mathrm{~mm}$. O fato do mês de junho ser o mais representativo em termos de precipitação pode estar relacionado aos sistemas meteorológicos intitulados de Ondas de Leste, pois de acordo com Silva (2007) as ondas de leste ocorrem com mais frequência entre os meses de maio a agosto. Em contrapartida, o período seco ocorre entre os meses de agosto a fevereiro, tendo outubro como o mês mais seco, com média de $8,0 \mathrm{~mm}$ de precipitação (Figura 6). 


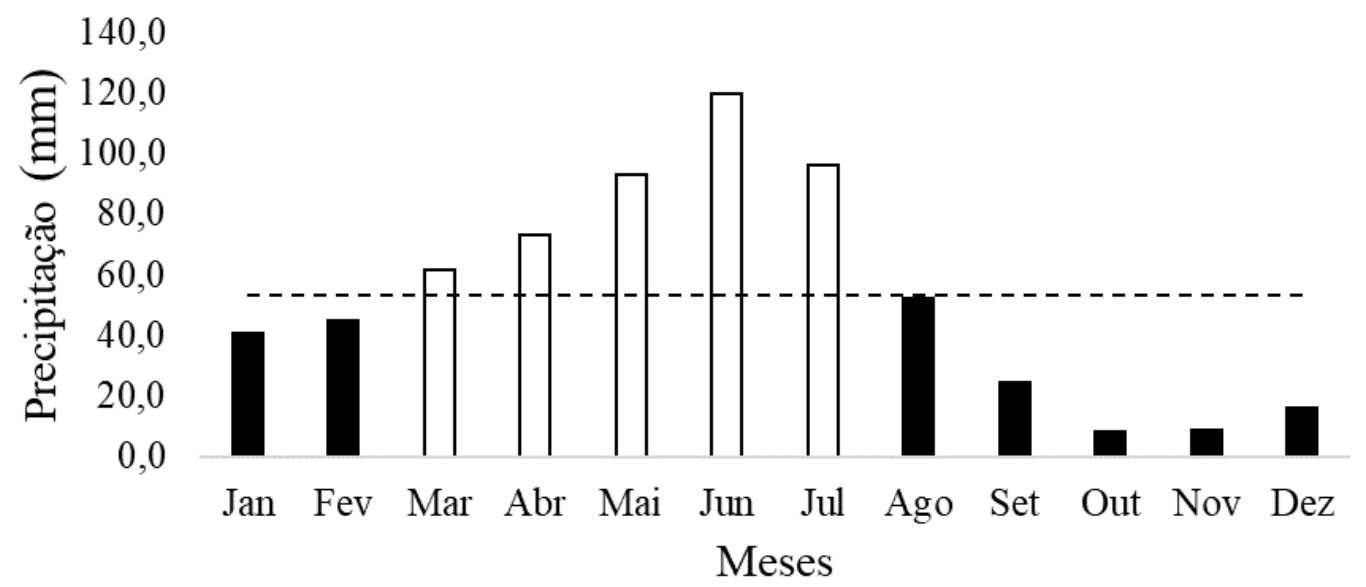

Figura 6 - Pluviograma de Precipitação mensal da área da Microrregião de Umbuzeiro.

A distribuição da precipitação média da microrregião de Umbuzeiro se destaca na Figura 7 , na qual $69 \%$ da precipitação faz parte do período úmido, esse fato é de fundamental importância, pois, a partir deste entendimento e conhecimento desses dados é que se pode elaborar e prospectar ações futuras para o desenvolvimento da microrregião de Umbuzeiro. Assim como destaca Silva et al., (2012) que o conhecimento da variabilidade inter e intra-anual da precipitação é bastante útil para vários propósitos, inclusive na formulação de táticas para implantações de culturas. Por outro lado, 31\%, da precipitação da microrregião encontra-se presente no período seco, desta forma é importante constatar que é necessário um planejamento apropriado, para que os municípios se previnam armazenando e suprindo assim a quantidade de água, para suprir uma futura escassez hídrica e dinamizar suas atividades sem interrupções.

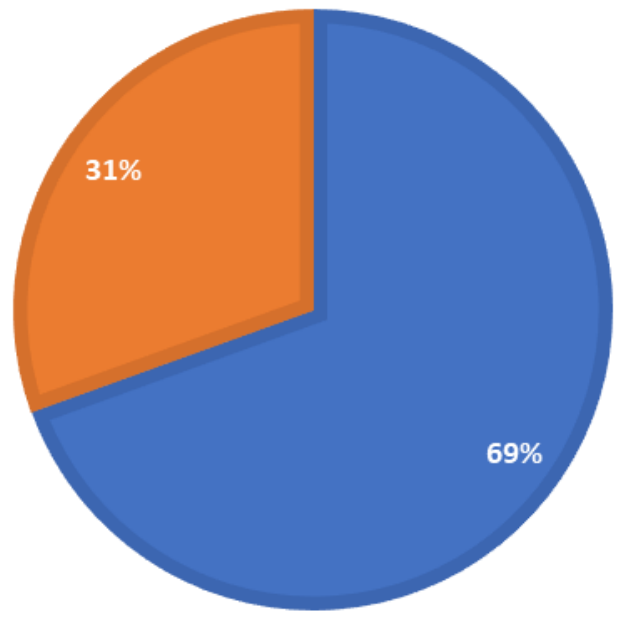

- Média do Período Chuvoso Média do Período Seco

Figura 7 - Percentual da precipitação da Microrregião de Umbuzeiro nas estações seca e chuvosa.

Através da série histórica, foi realizada a espacialização da precipitação acumulada da Microrregião de Umbuzeiro, (Figura 8). Verificou-se que os maiores valores de precipitação são observados no litoral, ou seja, na parte 
leste e sudeste com valores variando de 1000 a $1080 \mathrm{~mm}$, e pode-se notar que ao longo da microrregião a precipitação diminui no sentido de leste para oeste, tornando-se essas áreas menos chuvosas do que a área citada acima variando em até $350 \mathrm{~mm}$. Essa distribuição da precipitação ao longo da figura pode ajudar a entender de que maneiras as chuvas se portam ao longo da microrregião, e ajudar assim a favorecer as atividades humanas como também a flora e a fauna, através da abundância ou da sua escassez hídrica durante todo o ano.

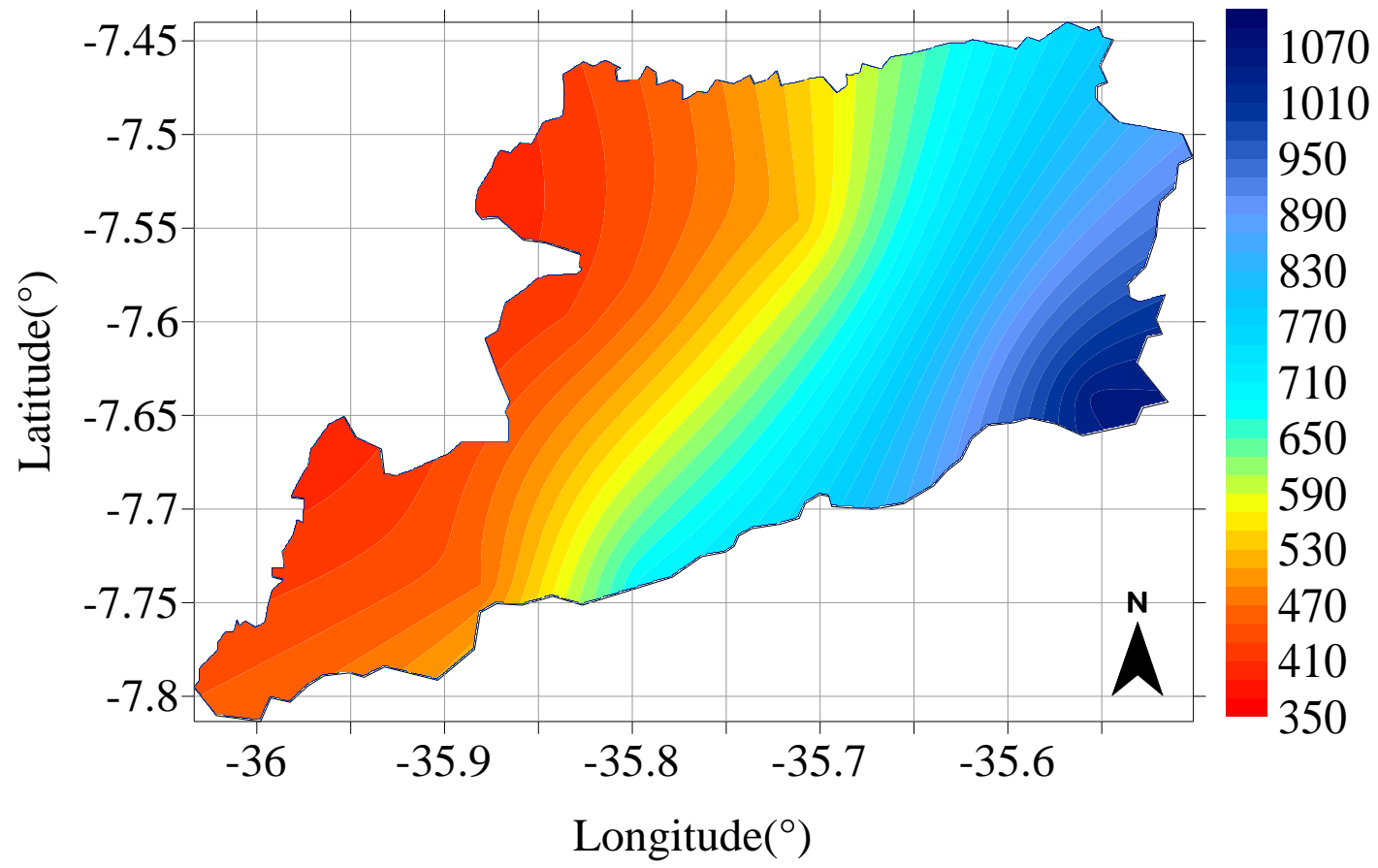

Figura 8 - Distribuição espacial da precipitação acumulada da microrregião de Umbuzeiro.

$\mathrm{Na}$ finalidade de melhor entender o comportamento dinâmico da precipitação analisou-se a espacialização da precipitação da microrregião de Umbuzeiro mensalmente, Figura $9(\mathrm{~A})$ a $9(\mathrm{~L})$.

Nas Isoietas médias mensais da microrregião de Umbuzeiro foi ilustrado o comportamento da precipitação de janeiro a dezembro, no qual o mês de janeiro (Figura $9 \mathrm{~A}$ ) representa um dos últimos meses da estação seca, sendo que nesse mês a parte leste apresenta seus valores máximos em $62,4 \mathrm{~mm}$ e ao longo da microrregião vai diminuindo sua precipitação chegando a parte central e noroeste com valores mínimos de $13 \mathrm{~mm}$. Para fevereiro (Figura 9 B) que é o último mês do período seco para o chuvoso, apresentam valores de precipitação máximos de $72 \mathrm{~mm}$ na parte leste da microrregião e valores mínimos de precipitação de aproximadamente $21 \mathrm{~mm}$ localizados nas áreas noroeste, oeste, sudoeste e uma pequena parte no norte.

Para março (Figura $9 \mathrm{C}$ ) mês no qual se inicia o período chuvoso na microrregião de Umbuzeiro, valores máximos atingem 96,7 mm na área leste e valores mínimos são observados na área sudoeste, com valores de $34,3 \mathrm{~mm}$. No mês de abril (Figura 9 D) a precipitação na microrregião varia com valores máximos em 112,4 mm na parte leste da microrregião e com valores mínimos 
de $53 \mathrm{~mm}$ localizados a noroeste, oeste e sudoeste. Para o mês de maio (Figura $9 \mathrm{E}$ ) valores máximos atinge cerca de aproximadamente $139 \mathrm{~mm}$ com seu ápice na região leste e com precipitação bem distribuída na microrregião e valores mínimos de precipitação na parte noroeste, oeste de aproximadamente $61 \mathrm{~mm}$.

Para junho (Figura 9 F) mês esse que ocorre o auge da estação chuvosa, de acordo com a Figura 4, mês de extrema importância para a microrregião de Umbuzeiro devido à precipitação ser bem acima da média do período, no qual, todo volume de precipitado dá suporte, direto ou indiretamente, a agricultura, a fauna e a flora local, ressaltando o abastecimento dos mananciais, açudes e lagoas da área estudada; desta forma, o mês em questão destacou-se com valores de precipitação entre 69 a 186,5 mm, no qual se encontra valores máximos na região leste com precipitação bem distribuída ao longo dos municípios e valores mínimos na parte noroeste. Para o mês de julho (Figura 9 G) que representa a transição do período chuvoso para o seco com o término da sua estação chuvosa e mês no qual ainda apresenta grande distribuição pluviométrica com valores máximos de $161 \mathrm{~mm}$ na área leste e valores mínimos de $46 \mathrm{~mm}$ na parte noroeste e sudoeste.

O mês de agosto (Figura $9 \mathrm{H}$ ) mês no qual se inicia a estação seca da microrregião estudada variando entre 16 a $99 \mathrm{~mm}$, no qual os valores máximos se distribuem na parte leste e valores mínimos na parte noroeste, sudoeste e oeste da microrregião. Para setembro (Figura 9 I) apresenta-se com valores máximos de precipitação na área leste de aproximadamente $53 \mathrm{~mm}$ e valores mínimos na parte noroeste com cerca de $7 \mathrm{~mm}$.

Os meses de outubro (Figura $9 \mathrm{~J}$ ), novembro (Figura $9 \mathrm{~K}$ ) e dezembro (Figura $9 \mathrm{~L}$ ) vale ser ressaltado que são os meses mais secos da microrregião com valores de precipitação em no máximo $28 \mathrm{~mm}$ e valores mínimos em 1,9 $\mathrm{mm}$, distribuído por toda área da microrregião de Umbuzeiro. Cabe destacar ainda que é de extrema importância que nesses meses os gestores dos municípios junto com os proprietários locais fiquem atentos a questão hídrica nos municípios, com uso racional e adequado deste recurso, gerando assim o equilíbrio ambiental, viabilizando as atividades humanas e favorecendo assim a fauna e flora local.

A

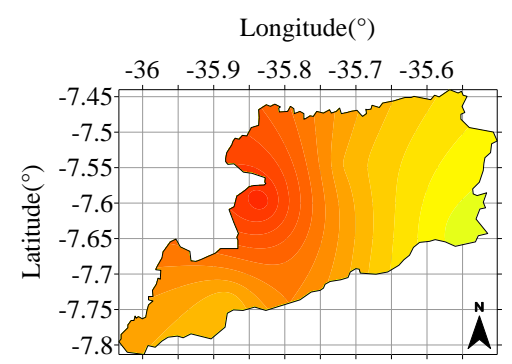

D

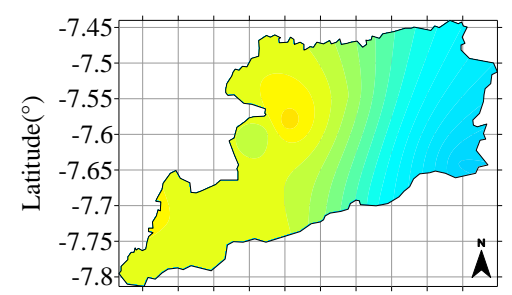

B

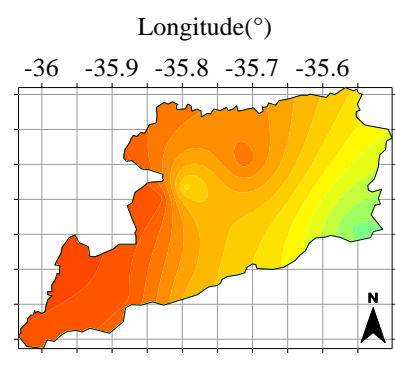

E

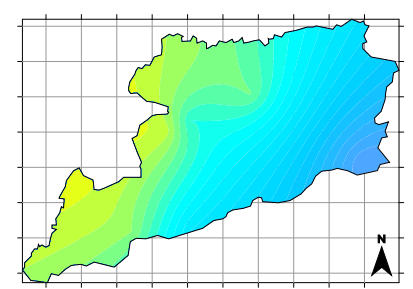

C

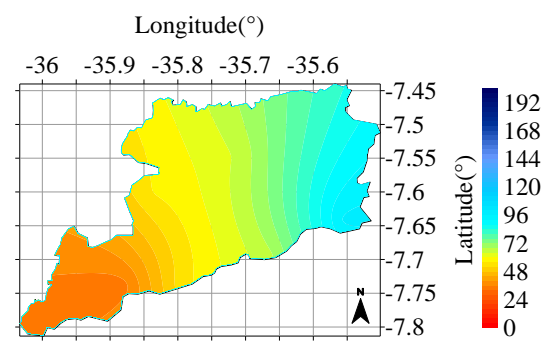

$\mathrm{F}$

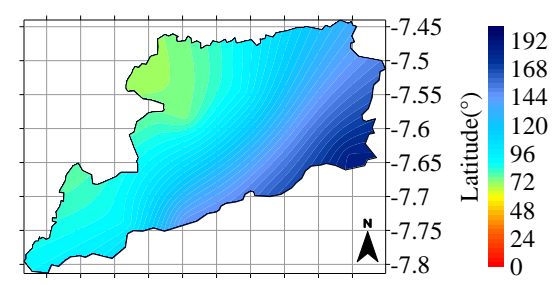


G

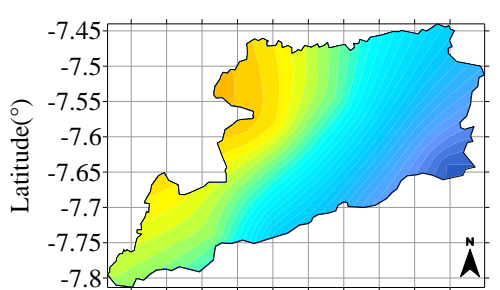

$\mathrm{K}$

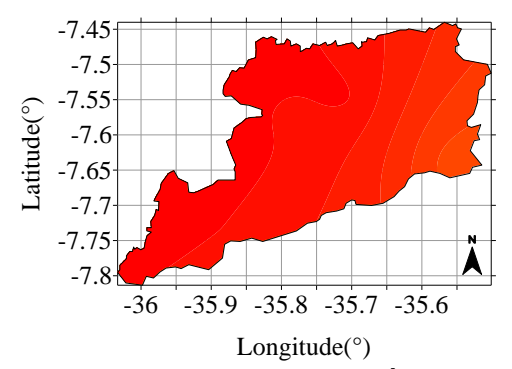

$\mathrm{H}$

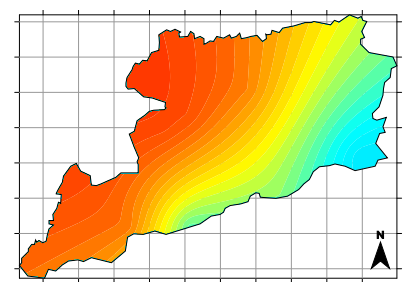

$\mathrm{K}$

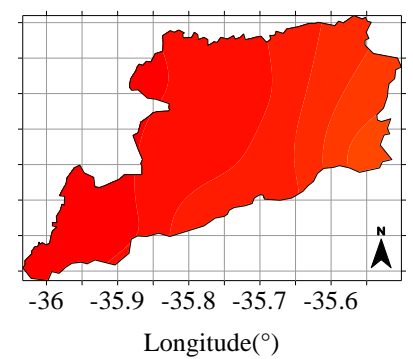

I

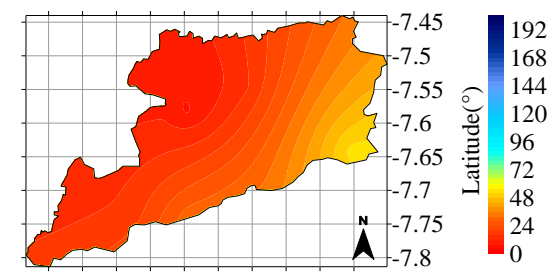

L

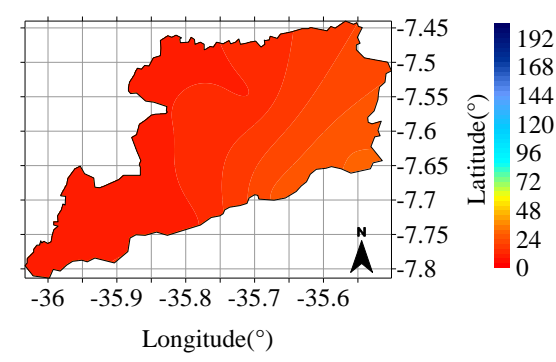

Figura 9 - Isoietas médias mensal da microrregião de Umbuzeiro de Janeiro $(A)$, Fevereiro (B), Março (C), Abril (D), Maio (E), Junho (F), Julho (G), Agosto (H), Setembro (I), Outubro (J), Novembro (K) e Dezembro (L).

Para melhor avaliar a variabilidade da precipitação, aplicou-se o Índice de Anomalia de Chuva (IAC), o qual avalia o grau de severidade dos eventos e de duração de períodos secos e úmidos da série histórica de precipitação. De acordo com a Figura 10, a série é composta por dez anos Chuvosos, que de acordo com a Tabela 1, foram classificados, variando entre as classes de UMIDO (1996, 1997, 2005, 2007, 2009 e 2010), MUITO ÚMIDO (1994) e EXTREMAMENTE ÚMIDO (2000, 2004 e 2011). Ainda de acordo com a mesma tabela, foram encontrados catorze anos secos, classificados como SECO (2001, 2002, 2003, 2008, 2013, 2014, 2015 e 2017), MUITO SECO (1995, 1999, 2006, 2012 e 2016) ou EXTREMAMENTE SECO (1998).

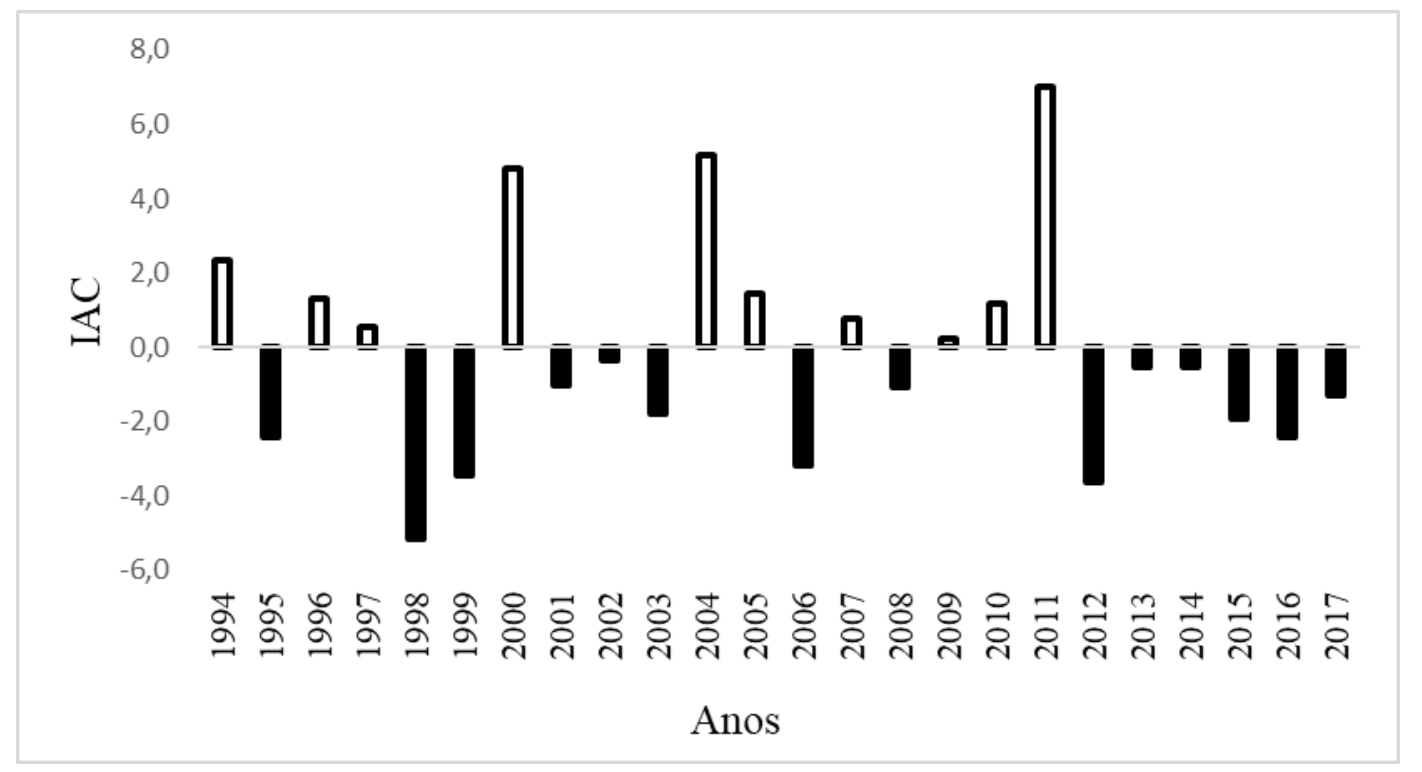

Figura 10 - Índice de anomalia de chuva (IAC) da Microrregião de Umbuzeiro. 
De acordo com o resultado observado acima pode-se ressaltar que os períodos secos podem estar associados a crise hídrica, ocasionando secas, prejudicando a agricultura pela falta de chuvas e na criação de animais. Já nos períodos úmidos podem acarretar problemas também na agricultura, enchentes nas cidades por falta de infraestrutura, dentre outros aspectos, corroborando assim com Souza e Azevedo, (2012) que afirmam que os fenômenos oriundos da variabilidade climática podem acarretar problemáticas também diferenciadas, a exemplo de secas e chuvas intensas, resultando em impactos na agricultura nos recursos hídricos, na saúde, e no meio ambiente. Entretanto, vale ainda ser enfatizada que em séries grandes ou pequenas de precipitação, o importante é a alternância de períodos chuvosos e secos, pois, deste modo se observará um equilíbrio ecológico entre o homem, a fauna e flora sem prejudicar as atividades e sua dinâmica natural de interação do homem com a natureza.

Durante a série histórica, verifica-se uma estabilidade entre o IAC com variações significativas entre anos positivos e negativos, levando a crer que durante a série histórica pode-se observar que os anos têm intervalos bemparecidos como os anos de (1996 e 1997) e (2009 a 2011) que se apresentaram como positivos e logo em sequência os anos de (1998 e 1999) e (2012 a 2014), que se apresentou negativo, observa-se que existem intervalos bem-parecidos a cada anos úmidos veem intervalos intercalados com anos secos.

Para melhor entender o comportamento desse índice, avaliou-se o seu comportamento intra-anualmente, entre os anos considerados extremos, dois anos secos e dois chuvosos, do qual vale ser ressaltado a sua variação dentro da estação seca e chuvosa dos anos analisados.

Os anos representados como Secos foram os anos de 1998 e 2012, anos que o IAC se mostrou negativo (Figura 11), observou-se que dentro do período seco que vai de agosto a fevereiro (Figura 6) 3 meses apresentaram-se com valor positivo, sendo eles os meses de agosto de 1998, janeiro e fevereiro de 2012, mostrando assim que dentro de anos bem secos, alguns meses não seguiram sua normalidade. Seguindo assim a sua variabilidade temporal em sua normalidade, com seis meses secos., porém, no semestre considerado mais úmido os meses de março e abril de 2012 obteve o IAC negativo corroborando com os resultados de Silva et al. (2009) que afirmam que o IAC, em anos secos, tende a ser mais negativo até mesmo no período chuvoso. 


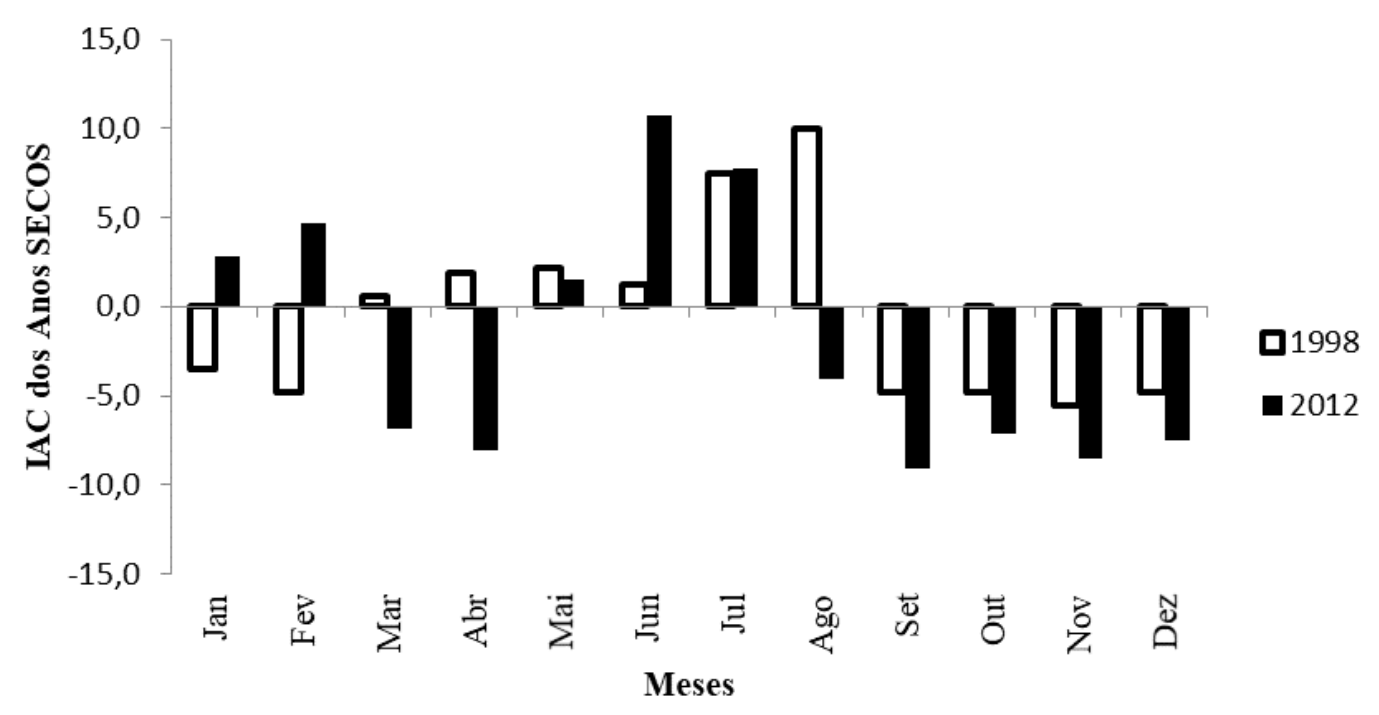

Figura 11 - Índice de anomalia de chuva (IAC) dos anos secos da Microrregião de Umbuzeiro

A Figura 12 mostra o IAC dos anos úmidos da Microrregião de Umbuzeiro que foram 2004 e 2011, ou seja, anos que o IAC se apresentou positivo. Podese observar que dentro do semestre seco os meses de janeiro e fevereiro de 2004 como também o mês de janeiro de 2011 apresentou valores positivos de IAC. Conforme Brito \& Braga (2005) as fortes chuvas de janeiro e fevereiro de 2004 foram ocasionadas pela interação entre a atividade convectiva produzida pelo Vórtice Ciclônico, a ZCAS (Zona de Convergência do Atlântico Sul) e pela ZCIT (Zona de Convergência Intertropical), outro fator que, além disso, pode ter motivado as intensas chuvas em janeiro e fevereiro de 2004, foi o aumento da Pressão ao Nível médio do Mar (PNM) no Atlântico Subtropical sul que pode, portanto, ter produzido um aumento de umidade para o Nordeste do Brasil, conforme Brito \& Braga (2005).

Já no período chuvoso os meses de março, abril e agosto de 2004 e os meses de junho e agosto de 2011 apresentaram IAC com valores negativos, mostrando que nesses anos úmidos também se obteve meses bem secos.

Pode se notar que para os anos úmidos específicos (2004 e 2011) três meses (janeiro e fevereiro de 2004 e janeiro de 2011) não obedeceram às características do período seco, mas dentro do semestre úmido cinco meses se apresentaram em desacordo com as características do período chuvoso, sendo eles março, abril e agosto de 2004, junho e agosto de 2011. 


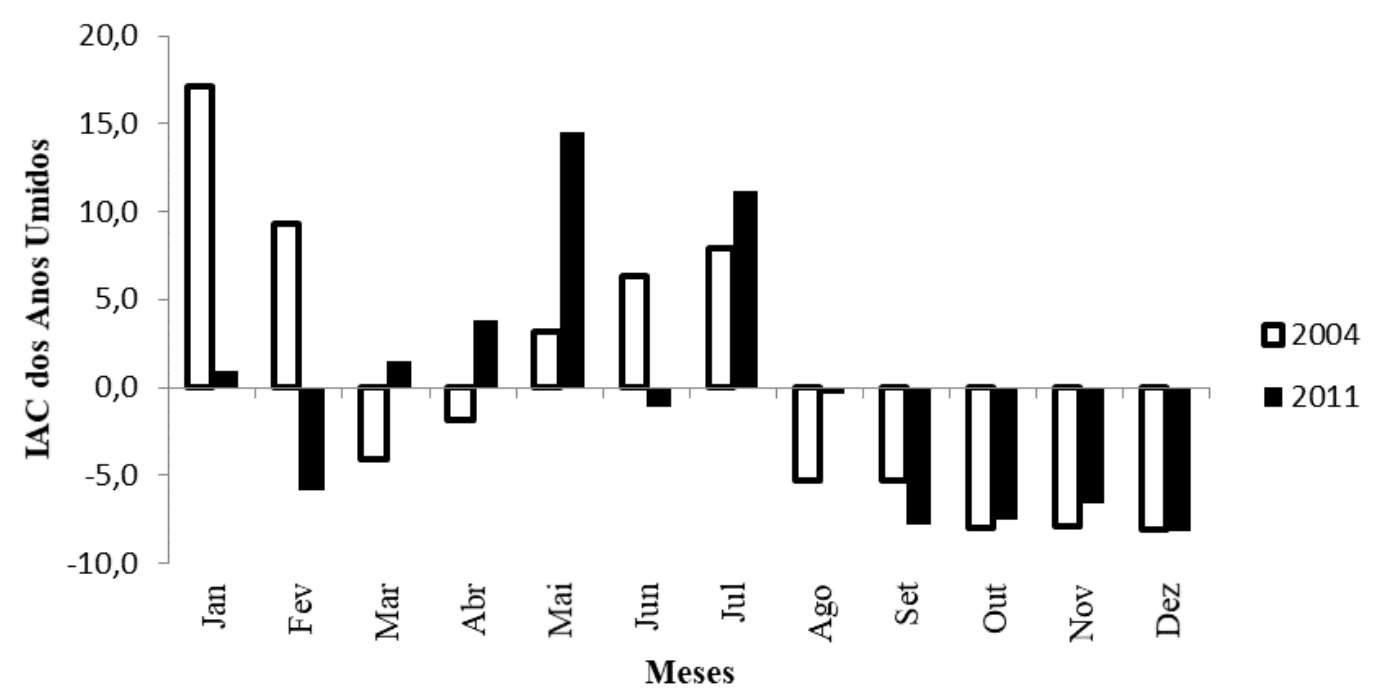

Figura 12 - Índice de anomalia de chuva (IAC) mensais de anos úmidos Microrregião de Umbuzeiro.

\section{CONCLUSÕES}

A climatologia temporal da microrregião de Umbuzeiro consta com dois períodos distintos, um período chuvoso que se estende de março a julho, sendo junho o mês mais representativo; e outro, o período seco que se estende de agosto a fevereiro, com outubro sendo o mês mais seco do período.

A climatologia espacial da microrregião de Umbuzeiro possui áreas específicas de distribuição de precipitação, a parte leste com mais abundância de chuvas, sendo assim mais úmida, e, em contrapartida, a parte oeste e noroeste com menor intensidade de chuvas, sendo assim a região mais seca.

O Índice de Anomalia de Chuva é uma ferramenta de importância significativa em todas as áreas ambientais, pois, evidencia que é uma metodologia importante para monitorar os períodos extremos (úmidos e secos), do mesmo modo ainda para acompanhar o comportamento de uma determinada região, bacia hidrográfica ou município. Portanto, só através dele foi possível evidenciar que na série histórica estudada, a microrregião de Umbuzeiro possui uma alternância entre anos secos e úmidos, deste modo se observa um equilíbrio ecológico entre o homem, a fauna e flora sem prejudicar as atividades e sua dinâmica natural de interação do homem com a natureza.

Diante do exposto, esse trabalho traz resultados de relevância para área da ecologia, que por meio desses contribuem para que gestores municipais, pequenos proprietários e agricultores tenham informação das épocas chuvosas, mais propícias às atividades agrícolas e entendimento também dos períodos de escassez, contribuindo assim para uma produtividade mais abundante e estruturação do homem do campo, ressaltando a convivência em harmonia com a flora e a fauna local, estabelecendo assim o equilíbrio entre as partes. 


\section{REFERÊNCIAS}

ARAÚJO, L. E.; BECKER, C. T.; PONTES, A. L. Periodicidade da precipitação pluviométrica no estado da Paraíba. In: XIII CONGRESSO BRASILEIRO DE AGROMETEOROLOGIA, 2003, Rio Grande do Sul. Anais II. Santa Maria: RS, p. $947-948,2003$.

ARAÚJO, L. E.; MORAES NETO, J. M. DE; SOUSA, F. DE A. S. Classificação da precipitação e da quadra chuvosa da Bacia do Rio Paraíba utilizando índice de anomalia de chuva (IAC). Ambi-Agua, v.4, p.93-110, 2009.

BRITO, J. I. B.; BRAGA, C. C. Chuvas no estado da Paraíba em 2004. Boletim SBMET, p.27-32, 2005.

DA SILVA, D.F. Analise de aspectos climatológicos, ambientais, agro econômicos e de se seus efeitos sobre a Bacia hidrográfica do rio Mundaú (AL e PE). 2009. 174 p. Tese de Doutorado em Recursos Naturais, Universidade Federal de Campina Grande. Campina Grande (PB). 2009.

EMPRESA BRASILEIRA DE PESQUISA AGROPECUÁRIA - EMBRAPA. Serviço Nacional de Levantamento e Conservação de Solos (Rio de Janeiro, RJ). Súmula da 10. Reunião Técnica de Levantamento de Solos. Rio de Janeiro:1979. 83p.

ESPINOZA, E. S. Distúrbios nos ventos de leste no Atlântico Tropical. 1996. Dissertação (Mestrado em Meteorologia) - Instituto Nacional de Pesquisas Espaciais, São José dos Campos. (INPE-6347 - TDI/598).

FREITAS, M. A. S. Um sistema de suporte à decisão para o monitoramento de secas meteorológicas em regiões semi-áridas. Revista Tecnologia, v.19, p.8495, 2005.

IBGE - Instituto Brasileiro de Geografia e Estatística. Contagem da população 2017. Brasília: IBGE, 2017. s.p.

KOUSKY, V. E. Frontal Influences on Northeast Brazil. Monthly Weather Review, v.107, p. $1140-1153.1979$

KOUSKY, V. E. e Gan, M. A. Upper tropospheric cyclonic vortices in the tropical South Atlantic. Tellus, v. 36, n. 6, p. 538-551, 1981.

NIKOLOVA, N. Regional climatechange: Precipitation variability in mountainous part of Bulgaria. Instituto Geográfico "jovancvijic" SASA. Coleção de Papeis, p.79-86, 2007.

ROOY, M. P. van. A Rainfallanomaly index independentof time andspace, Notos. V.14, p.43-48, 1965.

SANTOS, E. P.; CORREIA, M. F.; ARAGÃO, M. R. S.; SilVA, F. D. S. Eventos extremos de chuva e alterações no regime hidrológico da Bacia Hidrográfica do Rio São Francisco: Uma aplicação do índice RAI (Rainfall Anomaly Index). Engenharia Ambiental, v.8, p.315-330, 2011.

SILVA, L. L. Precipitações pluviais da pré-estação chuvosa no período chuvoso e suas influencias na produtividade agrícola na paraíba. Dissertação (Mestrado). Campina Grande/Pb. Programa de Pós-graduação em Meteorologia, UFCG. 2007. $144 p$. 
SILVA, D. F.; g F. A. S.; KAYANO M. T.; GALVÍnCIO J. D. Influência da variabilidade climática global e de suas escalas temporais sobre a precipitação no Alto Mundaú (PE). Revista Brasileira de Geografia Física, v.2, p.64-82, 2009.

SILVA V. P. R.; PEREIRA E.R. R.; ALMEIDA R. S. R. Estudo da variabilidade anual e intra-anual da precipitação na região Nordeste do Brasil. Revista Brasileira de Meteorologia, v.27, n.2, 163 - 172, 2012

SILVA FILHO, J. A.; FARIAS, C. A. S.; ARAÚJO, S. C. Análise temporal do comportamento da precipitação pluviométrica no município de Pombal - PB. In: WORKSHOP INTERNACIONAL SOBRE ÁGUA NO SEMIÁRIDO BRASILEIRO, 2., 2015, Campina Grande. Anais do I WORKSHOP INTERNACIONAL SOBRE ÁGUA NO SEMIÁRIDO BRASILEIRO. Campina Grande: REALIZE, v. 1, p. 1- 6, 2013.

SOUZA, W.M., AZEVEDO, P.V. Índices de detecção de mudanças climáticas derivados da precipitação pluviométrica e das temperaturas em Recife-PE. Revista Brasileira de Geografia Física 1, 143-159. 2012.

UVO, C. R. B. A Zona de Convergência Intertropical (ZCIT) e sua Relação com a Precipitação da Região Norte do Nordeste Brasileiro. Dissertação (Mestrado), Instituto Nacional de Pesquisas Espaciais (INPE). 99p.1989 